\title{
AIB e substratos no enraizamento de estacas de pessegueiro 'Okinawa' coletadas no outono
}

\author{
IBA and sustrates on the rooting of fall cuttings of 'Okinawa' \\ peach trees
}

\author{
Carina Cardoso ${ }^{1}$; Lilian Yukari Yamamoto ${ }^{1}$; Edilene Aparecida Preti ${ }^{1}$; Adriane \\ Marinho de Assis ${ }^{2}$; Carmen Silvia Vieira Janeiro Neves ${ }^{3}$; Sergio Ruffo Roberto ${ }^{3 *}$
}

\section{Resumo}

A propagação de porta-enxertos de pessegueiro é feita normalmente por meio de sementes, mas esse processo pode levar à perda de características genéticas desejáveis, como a resistência a nematóides do gênero Meloidogyne apresentada pelo porta-enxerto 'Okinawa'. O objetivo deste trabalho foi avaliar o enraizamento de estacas de pessegueiro 'Okinawa' tratadas com ácido indolbutírico (AIB) em diferentes substratos, no outono. As estacas foram submetidas à aplicação de AIB em três concentrações $(0 ; 1.000$ e $2.000 \mathrm{mg} \mathrm{L}^{-1}$ ) por imersão rápida da base das estacas, em três substratos (areia, vermiculita e casca de arroz carbonizada). A estaquia foi realizada em caixas plásticas contendo os substratos, em câmara de nebulização. $\mathrm{O}$ delineamento experimental foi o inteiramente casualizado, com 5 repetições em arranjo fatorial 3 x 3, sendo cada parcela composta por 10 estacas. Após 108 dias verificou-se que a aplicação de AIB na concentração de $2.000 \mathrm{mg} \mathrm{L}^{-1}$ mostrou-se mais eficiente no enraizamento das estacas de pessegueiro nos substratos casca de arroz carbonizada e vermiculita, com enraizamento de 58 a $68 \%$.

Palavras-chave: Prunus persica (L.) batsch, raízes, propagação, vermiculita, casca de arroz carbonizada

\begin{abstract}
The propagation of peach rooststocks is mainly done by seeds, but this method can result in the loose of interesting characteristics, like the resistance of 'Okinawa' rootstock to Meloidogyne spp. nematodes. The aim of this study was to evaluate the rooting of 'Okinawa' peach cuttings treated with different concentrations of indole butyric acid (IBA) on different substrates, in the fall. Cuttings of peach trees were subjected to application of IBA at three concentrations $\left(0,1000\right.$, and $\left.2000 \mathrm{mg} \mathrm{L}^{-1}\right)$ by rapid immersion of the cuttings in three substrates (sand, vermiculite, rice hulls). Cutting was performed in plastic boxes containing the substrates in a mist chamber. The experiment was randomized with 5 replications in a $3 \times 3$ factorial arrangement, where each plot was composed by 10 cuttings. After 108 days it was found that application of IBA at a concentration of $2000 \mathrm{mg} \mathrm{L}^{-1}$ was more effective on rooting of peach cuttings in the substrates carbonized hulls and vermiculite, with $58-68 \%$ of rooting.
\end{abstract}

Key words: Prunus persica (L.) batsch, roots, propagation, vermiculite, rice hulls

1 Alunos de Pós-Graduação em Agronomia, Centro de Ciências Agrárias, Universidade Estadual de Londrina, UEL, C P 6001, 86051-990, Londrina, PR. Bolsistas CAPES. E-mail: cari_cardoso@hotmail.com; edilenepretti2006@yahoo.com.br; domotokoichitsuyoshi@hotmail.com

2 Pós-Doutoranda, Universidade Estadual de Londrina, UEL, PR. Londrina, PR. Bolsita PNPD/CAPES. E-mail: agroadri@, ig.com.br

3 Profs. Drs. Associados da Universidade Estadual de Londrina. UEL, Dept ${ }^{\mathrm{o}}$ de Agronomia, Londrina, PR. Bolsista em Produtividade do CNPq. E-mail: csvjneve@uel.br; sroberto@uel.br

*Autor para correspondência

Recebido para publicação 24/05/2010 Aprovado em 01/07/2011 


\section{Introdução}

O pêssego e a nectarina estão entre as frutas de maior interesse econômico, sendo a China, a Itália e Estados Unidos os principais países produtores. Em 2008, a produção mundial foi de 18 milhões de toneladas e neste cenário, o Brasil ocupa o décimo segundo lugar com 240 mil toneladas colhidas, estando a produção concentrada principalmente na região Sul do país (CARAMORI et al., 2008; FAO, 2010).

Chalfun e Hoffmann (1997) descreveram que um dos fatores a ser considerado visando o aumento na produtividade do pessegueiro é a utilização de mudas de qualidade na implantação do pomar e, dentre os métodos de propagação, pode-se utilizar a enxertia de borbulhas em porta-enxertos oriundos de sementes (TOFANELLI; RODRIGUES; ONO, 2005). No entanto, um dos inconvenientes da propagação sexuada é a variabilidade genética devido à polinização cruzada, que pode acarretar a perda de características genéticas desejáveis, como a resistência a nematóides do gênero Meloidogyne apresentada pelo porta-enxerto 'Okinawa' (PEREIRA; NACHTIGAL; ROBERTO, 2002).

A propagação por estaquia possibilita a obtenção de várias plantas idênticas a partir de uma única planta matriz (FACHINELLO; HOFFMANN; NACHTGAL, 2005). Entretanto, vários fatores podem influenciar a capacidade e a rapidez no enraizamento das estacas, destacando-se os ambientais, o estado fisiológico, a maturação, o tipo de propágulo e a época de coleta da estaca (PAIVA; GOMES, 2001). Além destes, o potencial genético de cada cultivar também exerce influência no enraizamento (TREVISAN; SCHWARTZ; KERSTEN, 2000). Tofanelli et al. (2002) verificaram que a maioria das cultivares de pessegueiro produzidas no Brasil apresenta baixa capacidade de enraizamento, sendo necessário, portanto, a adoção de técnicas que estimulem a formação de raízes adventícias. Uma das alternativas é o uso de fitorreguladores, que segundo Fachinello, Hoffmann e Nachtgal (2005) tem aumentado a viabilidade da estaquia, principalmente em espécies de difícil enraizamento. Entre as auxinas sintéticas, o ácido indolbutírico (AIB) apresenta como vantagens a menor mobilidade e maior estabilidade química quando comparado ao ácido indolbutírico (AIA), além de ser menos fitotóxico que o ácido naftaleno acético (ANA) (FACHINELLO; HOFFMANN; NACHTGAL, 2005; SARZI; PIVETTA, 2005).

Outro fator preponderante para o sucesso da estaquia é a correta escolha do substrato, que servirá de suporte às mudas e deve apresentar características satisfatórias quanto ao suprimento de água e ar, capacidade de retenção de nutrientes, $\mathrm{pH}$ adequado e consistência para suporte, a fim de propiciar condições satisfatórias ao desenvolvimento das plantas (KÄMPF, 2000). Cooke (1999) e Rodrigues (2001) relataram que existe uma grande diversidade de substratos, mas o sucesso no uso depende da espécie e do ambiente de cultivo. Vários materiais vêm sendo testados como substrato para o pessegueiro, podendo ser indicado o Plantmax ${ }^{\circledR}$ na produção de 'seedlings' (JUNIOR et al., 2006), e vermiculita e areia para enraizamento de estacas (TOFANELLI; RODRIGUES; ONO, 2003).

Sendo assim, no intuito de otimizar as técnicas de propagação que permitam a manutenção das características genéticas desejáveis, possibilitando o aumento na formação de raízes adventícias em estacas no período do outono, o presente trabalho teve por objetivo avaliar o enraizamento de estacas semilenhosas do pessegueiro 'Okinawa' submetidas a diferentes concentrações de ácido indolbutirico (AIB), em três substratos.

\section{Material e Métodos}

O experimento foi conduzido no período de maio a agosto de 2009, no Departamento de Agronomia da Universidade Estadual de Londrina (UEL), Londrina (PR), localizada a $566 \mathrm{~m}$ de altitude, $23^{\circ} 23$, de Latitude Sul e $51^{\circ} 11$ de Longitude Oeste. 
Foram utilizadas estacas semilenhosas do pessegueiro 'Okinawa', de aproximadamente 10-12 cm de comprimento, com um par de folhas, retiradas das plantas pertencentes à coleção de pessegueiros da Fazenda Escola da Universidade Estadual de Londrina, coletadas em abril.

Foram estudadas três concentrações $(0,1.000$ e $2.000 \mathrm{mg} \mathrm{L}^{-1}$ ) de ácido indolbutírico (AIB) e 3 tipos de substratos (areia de granulação média, vermiculita de granulação média e casca de arroz carbonizada).

Antes de efetuar a coleta das estacas foi preparada a solução hidroalcóolica do AIB, pesando-se 0,1 e 0,2 g de AIB em balança semianalítica, e dissolvendo-se em $50 \mathrm{~mL}$ de álcool em um becker, com auxílio de agitador eletromagnético. Após totalmente dissolvido o AIB, completou-se o volume para $100 \mathrm{~mL}$ com água destilada, obtendose então a concentração de 1.000 e $2.000 \mathrm{mg} \mathrm{L}^{-1}$ de AIB.

O preparo das estacas consistiu de um corte em bisel logo abaixo de um nó. Durante o preparo das estacas, estas foram dispostas em recipientes com água para evitar a desidratação. Após o preparo, a porção basal das estacas foram imersas durante 10 segundos em solução hidro-alcoólica nas diferentes concentrações de AIB e imediatamente colocadas para enraizamento em caixas plásticas (com as dimensões 44 x $30 \times 7 \mathrm{~cm}$ ), contendo os substratos, em câmara de nebulização com regime intermitente controlado por temporizador e válvula solenóide. A válvula foi programada para nebulizar as estacas durante 10 segundos a cada intervalo de três minutos. O bico nebulizador empregado (Modelo Mist DanSprinkles, Israel) apresentou vazão de 35 L/hora. A câmara de nebulização estava inserida em estufa com cobertura de filme de polietileno transparente e sombrite $30 \%$.

O delineamento experimental utilizado foi o inteiramente casualizado, com cinco repetições em arranjo fatorial 3 × 3 (3 concentrações de AIB e 3 tipos de substratos), sendo cada parcela composta por 10 estacas.

Para o controle de doenças fúngicas, as estacas foram tratadas quinzenalmente com fungicidas sistêmicos a base de tebuconazol. Foi realizada, quinzenalmente, adubação foliar com fertilizante comercial Biofert Plus ${ }^{\circledR}$ (8-9-9 + micro) diluído na proporção de $5 \mathrm{~mL} \mathrm{~L}^{-1}$.

Após 108 dias da instalação do experimento, foram avaliados os parâmetros: sobrevivência das estacas ( $\%$ de estacas vivas); brotação ( $\%$ de estacas que emitiram brotos); estacas enraizadas (\% que emitiram pelo menos uma raiz); número de raízes por estaca (consideradas apenas aquelas que se originaram diretamente da estaca) e comprimento de raízes por estaca $(\mathrm{cm})$. Avaliou-se também o $\mathrm{pH}$ e condutividade elétrica dos substratos (KÄMPF; TAKANE; SIQUEIRA, 2006).

A partir dos dados obtidos foi avaliado o efeito dos fatores (concentração de AIB e substratos) através da análise de variância, e a comparação das médias foi realizada pelo teste de Tukey a $5 \%$ de probabilidade.

Efetuou-se a transformação dos dados em porcentagem pela equação arco-seno $\sqrt{\mathrm{x} / 100} \mathrm{e}$ para o número de raízes por estaca efetuou-se a transformação $\sqrt{\mathrm{x}+1}$.

\section{Resultados e Discussão}

Verifica-se que não houve interação entre as concentrações de AIB e os tipos de substratos quanto à porcentagem de sobrevivência e não foram observadas diferenças significativas entre esses fatores (Tabela 1). Em experimento com estacas de pessegueiro 'Okinawa', Camolesi et al. (2007) e Aguiar et al. (2005), também não observaram diferenças nas concentrações do AIB quanto à sobrevivência das estacas. 
Tabela 1. Sobrevivência das estacas (\%), estacas enraizadas (\%) e botação de estacas de pessegueiro 'Okinawa', submetidas ao preparo com diferentes concentrações de AIB e substratos, aos 108 dias da instalação do experimento. Londrina, Paraná, 2009.

\begin{tabular}{|c|c|c|c|c|c|c|}
\hline & \multirow{2}{*}{$\begin{array}{c}\text { Concentrações de AIB } \\
\qquad\left(\mathrm{mg} \mathrm{L}^{-1}\right)\end{array}$} & \multicolumn{3}{|c|}{ Substratos } & \multirow[b]{2}{*}{ Média } & \multirow[b]{2}{*}{$\mathbf{F}$} \\
\hline & & Areia & Vermiculita & CAC & & \\
\hline \multirow[t]{3}{*}{ Sobrevivência das estacas $(\%)^{\mathrm{a}}$} & 0 & 100,0 & 100,0 & 100,0 & $100,0 \mathrm{a}$ & \\
\hline & 1.000 & 98,0 & 100,0 & 100,0 & 99,3 a & $0,50 \mathrm{~ns}$ \\
\hline & 2.000 & 98,0 & 100,0 & 100,0 & $99,3 \mathrm{a}$ & \\
\hline Média & & $98,7 \mathrm{a}$ & $100,0 \mathrm{a}$ & $100,0 \mathrm{a}$ & & \\
\hline $\mathrm{F}$ & & & $2,00 \mathrm{~ns}$ & & & \\
\hline \multirow[t]{3}{*}{ Estacas enraizadas $(\%)^{\mathrm{a}}$} & 0 & $0,0 \mathrm{Aa}$ & $0,0 \mathrm{Ba}$ & $2,0 \mathrm{Ba}$ & 0,7 & $0,15 \mathrm{~ns}$ \\
\hline & 1.000 & $8,0 \mathrm{Aa}$ & $12,0 \mathrm{Ba}$ & $12,0 \mathrm{Ba}$ & 10,7 & $0,23 \mathrm{~ns}$ \\
\hline & 2.000 & $12,0 \mathrm{Ab}$ & $68,0 \mathrm{Aa}$ & $58,0 \mathrm{Aa}$ & 46,0 & $17,32 * *$ \\
\hline Média & & 6,7 & 26,7 & 24,0 & & \\
\hline $\mathrm{F}$ & & $2,14 \mathrm{~ns}$ & $18,32 * *$ & $29,83 * *$ & & \\
\hline \multirow[t]{3}{*}{ Brotação $(\%)^{\mathrm{a}}$} & 0 & 0,0 & 2,0 & 2,0 & $1,3 \mathrm{a}$ & $2,35 \mathrm{~ns}$ \\
\hline & 1.000 & 8,0 & 4,0 & 6,0 & $6,0 \mathrm{a}$ & \\
\hline & 2.000 & 2,0 & 6,0 & 12,0 & $6,7 \mathrm{a}$ & \\
\hline Média & & $3,3 \mathrm{a}$ & $4,0 \mathrm{a}$ & $6,7 \mathrm{a}$ & & \\
\hline $\mathrm{F}$ & & & $0,60 \mathrm{~ns}$ & & & \\
\hline
\end{tabular}

Médias seguidas por letras iguais mínúsculas nas linhas e maiúsculas nas colunas não diferem entre si pelo teste de Tukey $(\mathrm{p}<0,05)$. ns: não significativo; $* *=$ significativo $(\mathrm{p}<0,01) ;{ }^{\mathrm{a}}=$ dados transformados em arco-seno $\sqrt{\mathrm{X} / 100}$. CAC: Casca de arroz carbonizada.

Para a avaliação da porcentagem de enraizamento, a interação entre as concentrações de AIB e os tipos de substratos foi significativa (Tabela 1). No tratamento sem aplicação de AIB e na concentração $1.000 \mathrm{mg} \mathrm{L}^{-1}$ não houve diferença estatística entre os substratos testados; contudo, a concentração $2.000 \mathrm{mg} \mathrm{L}^{-1}$, resultou em maior percentual de enraizamento nos substratos vermiculita e casca de arroz carbonizada. Oliveira, Nienow e Calvete (2003) descreveram que o uso de reguladores de crescimento proporciona a melhoria no balanço hormonal das estacas, além da redução do tempo necessário para iniciar o enraizamento. Bentanin e Nienow (2010), trabalhando com estaquia de corticeira- da-serra (Erythrina falcata Benth.) verificaram que o uso do AIB proporcionou um estímulo ao enraizamento das estacas foliares. Além disso, Tofanelli et al. (2002) concluíram que uso do regulador de crescimento é indispensável para a melhoria dos índices de enraizamento de estacas semilenhosas de pessegueiro e Aguiar et al. (2005) também recomendaram o uso de AIB na concentração $2.000 \mathrm{mg} \mathrm{L}^{-1}$ e obtiveram 10 a $15 \%$ de enraizamento de estacas da cultivar Okinawa.

Com relação aos substratos, pode-se inferir que a maior aeração e retenção de umidade nos substratos vermiculita e casca de arroz carbonizada, aliada ao uso de AIB possibilitaram as melhores condições ao enraizamento das 
estacas. Nachtigal e Pereira (2000) demonstraram que os melhores resultados de enraizamento de estacas herbáceas de pesseguerio 'Okinawa' foram obtidos quando utilizaram vermiculita fina ou média $(87,6 \%$ e $80,6 \%$, respectivamente) e atribuíram estes resultados ao melhor equilíbrio na relação água/ar apresentado pela vermiculita.

Vale ressaltar que, embora tenha ocorrido o enraizamento das estacas neste experimento, os índices verificados (de 58 a 68\%) podem estar relacionados com a temperatura ambiente, pois durante a condução do experimento foram registradas temperaturas abaixo de $24^{\circ} \mathrm{C}$ (Figura 1), valor considerado ideal para estimular a divisão celular na área de enraizamento (HANSEN, 1989).

Figura 1. Médias referentes à temperatura $\left({ }^{\circ} \mathrm{C}\right)$ mínima e máxima na câmara de nebulização durante $\mathrm{o}$ período do experimento. Londrina, PR, 2009.

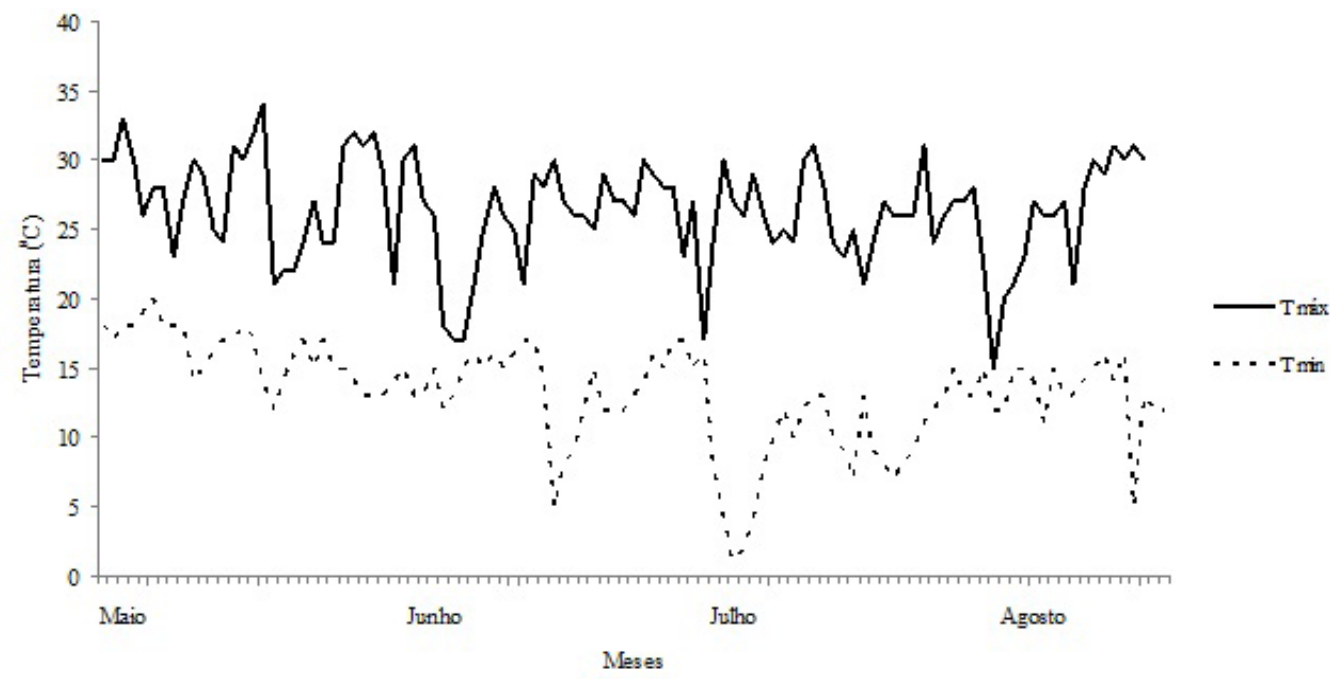

Quanto à porcentagem de brotação (Tabela 1), não houve interação entre as diferentes concentrações de AIB e os substratos, ao contrário do observado por Tofanelli, Rodrigues e Ono (2003), que verificaram que o equilíbrio na relação água/ar promovido pela vermiculita e areia foram favoráveis à brotação de estacas de pessegueiro 'Okinawa'.

Para as variáveis número e comprimento de raízes por estaca não houve interação significativa entre os fatores estudados (Tabela 2). As maiores médias foram observadas para $2.000 \mathrm{mg} \mathrm{L}^{-1}$, diferindo estatisticamente das demais concentrações de AIB quanto ao número de raízes por estaca. Esta mesma concentração conferiu às estacas o maior comprimento de raízes, diferindo estatisticamente dos resultados obtidos nas estacas não tratadas com AIB, confirmando o observado por Dutra, Kersten e Fachinello (2002), de que o AIB interfere na qualidade e quantidade de raízes produzidas. Hartmann e Kester (2002) afirmaram que o AIB estimula as plantas a produzirem raízes maiores, mais fortes e fibrosas. Entre os substratos, a vermiculita proporcionou maior número de raízes quando comparada à areia, que apresentou a menor média quanto ao comprimento de raízes das estacas. Estes resultados estão de acordo com Pereira, Nachtigal e Roberto (2002), que recomendaram o uso de vermiculita no enraizamento de estacas de pessegueiro 'Okinawa'. No entanto, Tofanelli, Rodrigues e 
Ono (2003) observaram que os substratos areia, vermiculita, e areia + vermiculita proporcionam os melhores resultados de brotação, número e comprimento de raizes em estacas lenhosas dessa mesma cultivar. Na produção de mudas em escala comercial, a emissão de raízes em maior número e comprimento é fator preponderante na constituição dos pomares, pois o sistema radicular bem formado favorece a absorção de nutrientes e água, propiciando, desta forma, um melhor desenvolvimento da muda no campo (FRACARO, 2004; ZIETEMANN; ROBERTO, 2007; CARVALHO JUNIOR; MELO; MARTINS, 2009). De acordo com Tavares, Kersten e Siewerdt (1995), o maior número, comprimento e massa seca de raízes favorecem o desenvolvimento das plantas e consequentemente, a qualidade das mudas formadas.

Tabela 2. Número de raízes por estacas e comprimento de raízes por estaca $(\mathrm{cm})$ da seleção de pessegueiro 'Okinawa', submetidas ao preparo com diferentes concentrações de AIB e substratos, aos 108 dias da instalação do experimento. Londrina, Paraná, 2009.

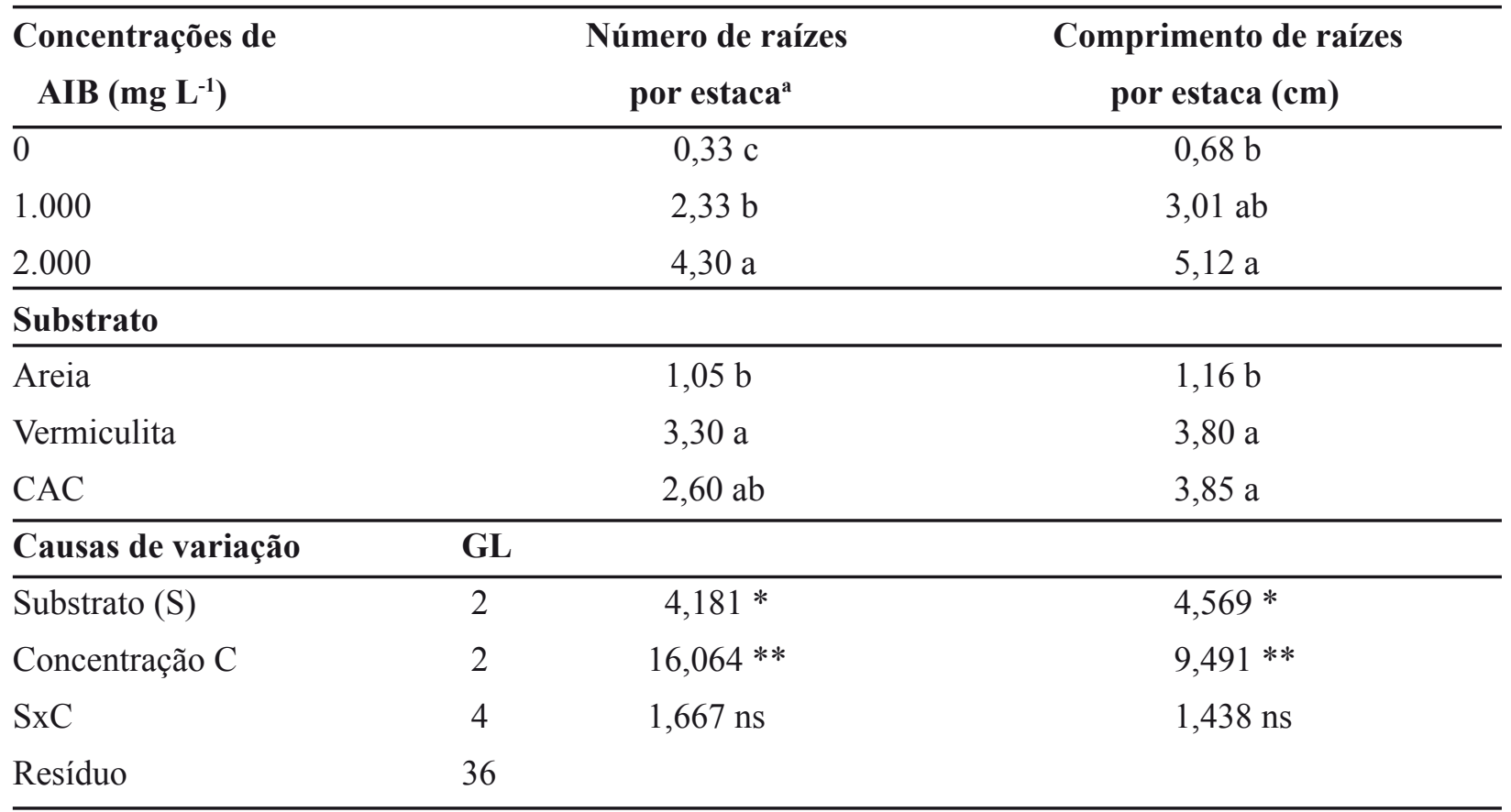

Médias seguidas por letras iguais nas colunas não diferem entre si pelo teste de Tukey $(p<0,05)$. ns: não significativo; $*=$ significativo $(\mathrm{p}<0,05) ; * *=$ significativo $(\mathrm{p}<0,01) ;{ }^{\mathrm{a}}=$ dados transformados $\sqrt{\mathrm{x}+1}$. CAC: Casca de arroz carbonizada.

Na avaliação do pH dos substratos (Tabela 3), verifica-se que as maiores médias foram obtidas nos substratos areia e vermiculita, diferindo estatisticamente da casca de arroz carbonizada. Fachinello, Hoffmann e Nachtgal (2005) citaram que o $\mathrm{pH}$ do substrato pode afetar o enraizamento das estacas, sendo que para algumas espécies a diminuição do $\mathrm{pH}$ favorece o enraizamento. Neste experimento, em função do curto período (108 dias) em que as estacas permaneceram no leito de enraizamento, os valores obtidos podem não ter interferido no processo de enraizamento das estacas. 
Tabela 3. Médias de pH e condutividade elétrica dos diferentes substratos, aos 108 dias da instalação do experimento. Londrina, Paraná, 2009.

\begin{tabular}{lcc}
\hline Substratos & pH & ${\text { Condutividade }\left(\boldsymbol{\mu S} . \mathbf{c m}^{-1}\right)}^{-103,60 \mathrm{~b}}$ \\
\hline Areia & $8,00 \mathrm{a}$ & $123,70 \mathrm{ab}$ \\
Vermiculita & $8,00 \mathrm{a}$ & $134,90 \mathrm{a}$ \\
CAC & $7,50 \mathrm{~b}$ & 16,42 \\
CV $(\%)$ & 3,88 & \\
\hline
\end{tabular}

Médias seguidas por letras iguais nas colunas não diferem entre si pelo teste de Tukey $(\mathrm{p}<0,05)$. CAC: Casca de arroz carbonizada.

Quanto à condutividade elétrica (Tabela 3), a maior média foi observada no substrato casca de arroz carbonizada, diferindo estatisticamente da areia. Ressalta-se, porém que, todos os valores estão classificados como ideais para substratos de mudas em bandejas, segundo Ballester-Olmos (1993), que descreve valores entre 75-200 $\mu{\mathrm{S} . \mathrm{cm}^{-1}}^{-1}$.

Com base nos resultados pôde-se observar que o enraizamento de estacas pessegueiro 'Okinawa' pode ser obtido com sucesso no período do outono, mediante a utilização de AIB na concentração 2000 mg L ${ }^{-1}$, nos substratos casca de arroz carbonizada e vermiculita, que, por apresentarem menor densidade em relação à areia, facilitam as operações de manejo das bandejas na estufa. No entanto, para a produção de mudas em escala comercial pode haver dificuldade na obtenção de grandes quantidades da casca de arroz carbonizada, o que não ocorre com a vermiculita, por ser um substrato comercial.

\section{Conclusão}

A propagação de pessegueiro 'Okinawa' por estaca semilenhosa pode ser realizada no outono, mediante utilização de AIB na concentração de 2000 mg L ${ }^{-1}$, nos substratos casca de arroz carbonizada e vermiculita, obtendo-se 58 a $68 \%$ de enraizamento.

\section{Agradecimentos}

À Coordenação de Aperfeiçoamento de Pessoal de Nível Superior (CAPES) e ao Conselho Nacional de Desenvolvimento Científico e Tecnológico (CNPq), pela concessão das bolsas.

\section{Referências}

AGUIAR, R. S. de; SANTOS, C. E. dos; ZIETEMANN, C.; ASSIS, A. M. de; MORAIS, V. J. de; ROBERTO, S. R. Enraizamento de estacas semilenhosas do pessegueiro 'Okinawa' submetidas a diferentes dosagens de ácido indolbutírico. Acta Scientiarum Agronomy, Maringá, v. 27, n. 3, p. 461-466, jul./set. 2005.

BALLESTER-OLMOS, J. F. Substratos para el cultivo de plantas ornamentales. Valencia: Saljen, 1993.

BENTANIN, L.; NIENOW, A. A. Propagação vegetativa da corticeira-da-serra (Erythrina falcata Benth.) por estaquia caulinar e foliar. Semina: Ciências Agrárias, Londrina, v. 31, n. 4, p. 871-880, out./dez. 2010.

CAMOLESI, M. R.; UNEMOTO, L. K. P.; SACHS, J. D.; ROBERTO, S. R.; SATO, A. J.; FARIA, A. P.; RODRIGUES, E. B.; SILVA, J. V. da. Enraizamento de estacas semilenhosas de pessegueiro "Okinawa" sob efeito de lesão e ácido indolbutírico. Ciência Rural, Santa Maria, v. 37, n. 6, p. 1805-1808, 2007.

CARAMORI, P. H.; CAVIGLIONE, J. H.; WREGE, M. S.; HERTER, F. G.; HAUAGGE, R.; VES, S. L. G.; CITADIN, I.; RICCE, W. da S. Zoneamento agroclimático para o pessegueiro e a nectarineira no Estado do Paraná. Revista Brasileira de Fruticultura, Jaboticabal, v. 30, n. 4, p. 1040-1044, dez. 2008.

CARVALHO JUNIOR, W. G. O.; MELO, M. T. P. de; MARTINS, E. R. Comprimento da estaca no desenvolvimento de mudas de alecrim-pimenta. Ciência Rural, Santa Maria, v. 39, n. 7, p. 2199-2202, out. 2009.

CHALFUN, N. N. J.; HOFFMANN, A. Propagação do pessegueiro e da ameixeira. Informe Agropecuário, Belo 
Horizonte, v. 18, n. 189, p. 23-29, 1997.

COOKE, R. B. Estufas e telados. Revista Oficial da Orquidário, Rio de Janeiro, v. 13, n. 3/4, p. 94-101, 1999.

DUTRA, L. F.; KERSTEN, E.; FACHINELLO, J. C. Época de coleta, ácido indol butírico e triptofano no enraizamento de estacas de pessegueiro. Scientia Agrícola, Piracicaba, v. 59, n. 2, p. 327-333, 2002.

FACHINELLO, J. C.; HOFFMANN, A.; NACHTGAL, J. C. Propagação de plantas frutíferas. Brasília: Embrapa Informações Tecnológicas, 2005. 221 p.

FOOD AND AGRICULTURE ORGANIZATION OF UNITED NATIONS - FAO. Statistics. Disponível em: $\quad<$ http://faostat.fao.org/site/567/DesktopDefault. aspx?PageID=567\#ancor $>$. Acesso em: 20 jan. 2010 .

FRACARO, A. A.; PEREIRA, F. M. Distribuição do sistema radicular da goiabeira 'Rica' produzida a partir de estaquia herbácea. Revista Brasileira de Fruticultura, Jaboticabal, v. 26, n. 1, p. 183-185, abr. 2004.

HANSEN, J. Influence of position and temperature during rooting of adventitious root formation and axilary bud break of Stephanotis floribunda. Scientia Horticulturae, Amsterdam, v. 40, n. 4, p. 345-354, 1989.

HARTMANN, H. T.; KESTER, D. E. Plant propagation: principles and practices. 7. ed. New Jersey: PrenticeHall, 2002, 880 p.

JUNIOR, A. W.; PIMENTEL, L. D.; NEGREIROS, J. R. da S.; ALEXANDRE, R. S.; MORGADO, M. A. D.; SILVA, J. O. da C. e; BRUCKNER, C. H. Influência do estádio de maturação dos frutos e do substrato na formação de seedlings de três cultivares de pessegueiro. Revista Brasileira de Agrociência, Pelotas, v. 12, n. 2, p. 221-225, abr/jun. 2006.

KÄMPF, A. N.; TAKANE, R. J.; SIQUEIRA, P. T. V. Floricultura: técnicas de preparo de substratos. Brasília: LK Editora e Cominicação, 2006. 132 p.

KÄMPF, A. N. Produção comercial de plantas ornamentais. Guaíba: Agropecuária, 2000. 254 p.

NACHTIGAL, J. C.; PEREIRA, F. M. Propagação do pessegueiro (Prunus persica (L.) Batsch) cv. Okinawa por meio de estacas herbáceas em câmara de nebulização em Jaboticabal. SP. Revista Brasileira de Fruticultura, Jaboticabal, v. 22, n. 2, p. 208-212, 2000.

OLIVEIRA, A. P. de; NIENOW, A. A.; CALVETE, E. de O. Capacidade de enraizamento de estacas semilenhosas e lenhosas de cultivares de pessegueiro tratadas com AIB. Revista Brasileira de Fruticultura, Jaboticabal, v. 25, n. 2, p. 282-285, ago. 2003.

PAIVA, H. N.; GOMES, J. M. Propagação vegetativa de espécies florestais. Viçosa, MG: Universidade Federal de Viçosa, 2001. (Série Cadernos Didáticos, 83).

PEREIRA, M. P.; NACHTIGAL, J. C.; ROBERTO, S. R. Tecnologia para a cultura do pessegueiro em regiões tropicais e subtropicais. Jaboticabal: Funep, 2002. 62 p.

RODRIGUES, V. T. Substratos e cultivo. Boletim da Coordenadoria das Associações Orquidófilas do Brasil $(C A O B)$, Rio de Janeiro, n. 44, p. 50-54, 2001.

SARZI, I.; PIVETTA, K. F. L. Efeito das estações do ano e do ácido indolbutírico no enraizamento de estacas de variedades de minirroseira (Rosa spp.). Científica, Jaboticabal, v. 332, n. 1, p. 62-68, 2005.

TAVARES, M. S. W.; KERSTEN, E.; SIEWERDT, F. Efeitos do ácido indolbutírico e da época de coleta no enraizamento de estacas de goiabeira (Psidium guajava L.). Scientia Agrícola, Piracicaba, v. 52, n. 2, p. 310-317, ago. 1995.

TOFANELLI, M. B. D.; CHALFUN, N. N. J.; HOFFMANN, A.; CHALFUN JÚNIOR, A. Efeito do ácido indolbutírico no enraizamento de estacas de ramos semilenhosos de pessegueiro. Pesquisa Agropecuária Brasileira, Brasília, v. 36, n. 7, p. 939-944, 2002.

TOFANELLI, M. B. D.; RODRIGUES, J. D.; ONO, E. O. 2,6-Di-hidroxiacetofenona e tipo de corte basal no enraizamento de estacas semi-lenhosas de pessegueiro Okinawa. Ciência Rural, Santa Maria, v. 35, n. 2, p. 462464, 2005.

Enraizamento de estacas lenhosas de pessegueiro cv. Okinawa em diferentes diâmetros de ramos, substratos e recipientes. Ciência Rural, Santa Maria, v. 33, n. 3, p. 437-442, maio/jun. 2003.

TREVISAN, R.; SCHWARTZ, E.; KERSTEN, E. Capacidade de enraizamento de estacas de ramos de pessegueiro (Prunus persica (L.) Batsch) de diferentes cultivares. Revista Científica Rural, Bagé, v. 5, n. 1, p. 29-33, 2000.

ZIETEMANN, C.; ROBERTO, S. R. Efeito de diferentes substratos e épocas de coleta no enraizamento de estacas herbáceas de goiabeira, cvs. paluma e século XXI. Revista Brasileira de Fruticultura, Jaboticabal, v. 29, n. 1, p. 31-36, abr. 2007. 